\section{Neuropathic pain treatment: still a challenge}

\author{
Osvaldo J.M. Nascimento, ${ }^{1}$ Bruno L. \\ Pessoa,1 Marco Orsini,2 Pedro Ribeiro,2 \\ Eduardo Davidovich, 1 Camila Pupe, 1 \\ Pedro Moreira Filho, 1 \\ Ricardo Menezes Dornas, 1 \\ Lucas Masiero,1 Juliana Bittencourt,2 \\ Victor Hugo Bastos 3 \\ 1Neuropathic Pain Division, \\ Neurology/Neuroscience Clinical \\ Research Subunit, Antonio Pedro \\ University Hospital, Federal Fluminense \\ University, Niterói; 2Brain Mapping \\ Department, Federal University of Rio de \\ Janeiro, IPUB, Rio de Janeiro; \\ Department of Medicine, Severino \\ Sombra University, Vassouras, Rio de \\ Janeiro; 3Piaui Federal University, \\ Physical Therapy School, Brazil
}

\section{Abstract}

Neuropathic pain (NP) is the result of a series of conditions caused by diseases or lesions to the somatosensory system. Due to the better understanding of NP pathophysiology previously unexplored therapies have been used with encouraging results. In this group, acetyl-L-carnitine, alpha-lipoic-acid, cannabinoids, clonidine, EMA401, botulinum toxin type A and new voltage-gated sodium channel blockers, can be included. Besides, changing paradigms may occur with the advent of optogenetics and a better understanding of epigenetic regulation. We reviewed the published literature on the pharmacological treatment of NP. Despite the interesting results, randomized controlled trials are demanded the majority of the therapies previously mentioned. In spite of several studies for the relief of NP, pain control continues being a challenge.

\section{Introduction}

Neuropathic pain (NP) is a condition due to diseases or lesions affecting the somatosensory nervous system pathways, either in the central or the peripheral nervous systems. ${ }^{1}$ Peripheral NP is the result of small fibers dysfunction or lesions seen in polyneuropathies (diabetes, chronic alcohol abuse, infections, chemotherapy, amyloidosis, etc.). Other frequent causes include trigeminal neuralgia, herpes zoster, complex regional pain syndrome (CRPS), entrapment syndromes, and others. ${ }^{2}$
Differently, central NP is infrequent, including pain due to spinal cord injury; pain is multiple sclerosis (MS), post-stroke pain, and etc. ${ }^{2}$

Usually, patients with NP can present with lancinating, shooting and/or burning pain along with tingling sensation. Positive sensory symptoms such as spontaneous or evoked pain in response to noxious or non-noxious stimuli (hyperalgesia and allodynia, respectively) may also occur. ${ }^{3,4}$ Besides, a well-performed history and physical examination are the best tools for the correct diagnosis. Electrophysiological tests, imaging, and at times histological examination points to the diagnosis, although NP is still diagnosed based on clinical aspects. ${ }^{4}$

Initially, the management of NP consists of drug therapy and interdisciplinary approaches. As the last resource, surgical intervention might be demanded, mainly in patients with refractory NP.5,6 This review will focus on new pharmacological treatments for NP.

\section{Pharmacological interventions}

The pharmacological treatment of NP is based on antidepressant and antiepileptic drugs. Still, opioid use can also be considered, but are commonly regarded controversial. These drugs are well studied and established in clinical practice, but their estimated pain relief is not higher than $40-50 \% .{ }^{6}$ Also, placebo effects may range from $30 \%$ bringing uncertainty about the effectiveness of these drugs in some patients. We have been observed this effect in real life and a daily basis. ${ }^{7}$ Among the new therapeutic options, some studies have been highlighted Acetyl-L-carnitine (ALC), Alpha-lipoic-acid (ALA), cannabis products, botulinum toxin and angiotensin type 2 receptor antagonists. ${ }^{6}$ Additionally, the new voltagegated sodium channel blockers, among which we highlight Nav1.7, Nav1.8, Nav1.3, and Nav1.9, are expected to be superior to other sodium channel blockers. Since these NAV's are receptor specific, they may lead to less potential cardiac, motor, and CNS side effects. ${ }^{8}$ In the same way, the use of specific blockers of the alpha-2-delta-1 (Cav 2 1) subunit of calcium channels has been studied as a potential antinociceptive drug, based on the concept of these channels might be overexpressed in some pain states. ${ }^{9}$ Till now, there is a lack of enough evidence regarding the efficacy of the majority of these emerging treatments for NP. Nevertheless, the paucity of randomized controlled trials (RCTs) and clinical evidence does not mean that we should abandon these new modalities. Instead, new studies are demanded to prove their efficacy. ${ }^{10,11}$

[Neurology International 2016; 8:6322]
Correspondence: Bruno Lima Pessoa, Neuropathic Pain Division of the Neurology/Neuroscience Clinical Research Subunit of Antonio Pedro University Hospital, Universidade Federal Fluminense (UFF), RuaSiqueira Campos, 53/1204, Copacabana, Rio de Janeiro, RJ, 22031-071 Brazil.

E-mail: blimapessoa@gmail.com

Key words: Neurology; pain; treatment.

Contributions: the authors contributed equally.

Conflict of interest: the authors declare no potential conflict of interest.

Received for publication: 24 November 2015 . Accepted for publication: 6 June 2016.

This work is licensed under a Creative Commons Attribution NonCommercial 4.0 License (CC BYNC 4.0).

(C) Copyright O. J.M. Nascimento et al., 2016

Licensee PAGEPress, Italy

Neurology International 2016; 8:6322

doi:10.4081/ni.2016.6322

\section{Acetyl-L-carnitine}

ALC is an ester produced by the human brain, liver, and kidney. ALC seems to increase the uptake of Acetyl-CoA into the mitochondria and exerts cholinomimetic effects because it is similar in structure to acetylcholine.12,13 In a controlled randomized trial performed by Sima Anders and colleagues, ${ }^{13}$ ALC was demonstrated to be efficacious in reducing NP, as well as improving nerve fiber regeneration in patients with diabetic neuropathy. ${ }^{13}$

Nevertheless, De Grandis and Minardi ${ }^{14}$ observed similar results in a multicenter, randomized, double-blind, placebo-controlled study including 333 diabetic patients with diabetic neuropathy. Randomization occurred to receive either ALC or a placebo. The active treatment group received $1 \mathrm{~g}$ of intramuscularly ALC for ten days following $2 \mathrm{~g}$ of orally ALC for 355 days. The ALC group demonstrated a $39 \%$ decrease in pain measured by VAS ( $\mathrm{P}<0.01$ vs. baseline) in 12 months; vs. $8 \%$ reduction in the placebo group. Significant change in nerve conduction velocity was found in sural nerve $(+7 \mathrm{~m} / \mathrm{sec}$ in ALC $v s .+1 \mathrm{~m} / \mathrm{sec}$ in placebo) and in the sensory ulnar nerve $(+2.9 \mathrm{~m} / \mathrm{sec}$ in LAC $v s .+0,1 \mathrm{~m} / \mathrm{sec}$ in placebo). 14

Alpha-lipoic-acid

ALA is known for its antioxidant properties 
and its role in mitochondrial dehydrogenase reactions. ALA has demonstrated protection against oxidative stress in models of ischemiareperfusion lesion, diabetes, neurodegeneration, HIV activation and others. Recent studies suggest that ALA plays a much broader role than just simply being an antioxidant. 15,16

A multicenter, randomized, double-blind, placebo-controlled trial with 181 diabetic patients tested daily dose of $600 \mathrm{mg}, 1200 \mathrm{mg}$, and $1800 \mathrm{mg}$ of oral ALA, or placebo for NP. A real pain reducing response with fewer side effects was found with the $600 \mathrm{mg}$ dose. Furthermore, thioctic acid has a functional structure very similar to ALA and can be expected to have similar benefits to that of ALA. 17,18

\section{Cannabinoids products}

In a randomized trial using smoked cannabis for chronic NP, the authors selected 23 patients. They concluded that a single inhalation of $25 \mathrm{mg}$ of $9.4 \%$ tetrahydrocannabinol herbal cannabis three times daily for five days may cause pain relief, improve the quality of sleep and is well tolerated. ${ }^{19,20}$

In another study, patients with MS were tested by using an oral spray with $2.7 \mathrm{mg}$ of tetrahydrocannabinol and 2.5 of delta-9cannabidiol. After five weeks, cannabis spray was superior to placebo in reducing pain and sleep disorders in MS patients with and central pain. Despite these results, controversies are still present related to cannabinoids use, since other randomized study did not reveal significant results, but instead showed same effects as the placebo group. ${ }^{21,22}$

In a systematic review and meta-analysis about cannabinoids for medical use, Whiting et al. showed only moderate evidence for the use of cannabinoids in chronic pain conditions and spasticity. However, its usage was related to significant short-term side effects. ${ }^{23}$

\section{Topical treatment: clonidine}

Clonidine has emerged as adjuvant therapy in diabetic patients who suffer from painful diabetic neuropathy. In a randomized, doubleblind, placebo-controlled study, Campbell and colleagues 24 included 179 patients with painful diabetic neuropathy to receive either $0.1 \%$ topical clonidine gel or placebo gel. As a result, patients who received topical clonidine gel obtained pain relief in the foot when compared to placebo. 6,24

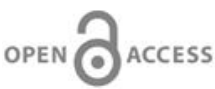

\section{Selective angiotensin II type 2- receptor antagonist: EMA401}

This class of drug is considered a new alternative for NP. EMA401 is a selective angiotensin II type 2-receptor antagonist. In a randomized, controlled, double blind, clinical trial 181 patients received $100 \mathrm{mg}$ EMA401 twice daily or a placebo. 25 The researchers found significantly less pain, after a week, compared with baseline values in the EMA401 group, compared to the placebo group, leading to a new possibility of treatment for refractory NP. ${ }^{25}$

\section{Cebranopadol}

This agent is an analgesic nociceptin/ orphanin FQ peptide (NOP) as well as an opioid receptor agonist. It has high antinociceptive and anti-hypersensitive effects without causing respiratory and motor side effects. In many rat models of acute and chronic pain (tail-flick, rheumatoid arthritis, bone cancer, spinal nerve ligation, diabetic neuropathy) its results have been proven positive for ameliorating NP. ${ }^{26}$ In spite of this, other studies are necessary before the usage in humans becomes possible.

\section{Botulinum toxin type $A$}

Botulinum Toxin type A (BTX-A) has been a subject of some studies for NP.27,28 Ranoux, Attal and colleagues 27 investigated the effect of intradermal injection of BTX-A in 29 patients with NP and allodynia of different etiologies. The BTX-A injection improved the spontaneous pain from 2 weeks to 12 weeks (NNT) of 3.03 for $50 \%$ pain relief), and reduced allodynia without decrease of sensibility to pain. ${ }^{27}$ In a double-blind crossover trial of intradermal BTX-A for diabetic NP in 18 patients, Yuan et $a l .28$ found a reduction in $\mathrm{VAS} \geq 3$ after 3 months of $44 \%$ of the patients who received BTX-A injection compared to the placebo arm of the study. Also, improvement in sleep quality in those patients was noted. Despite the exciting results, the authors agree that larger samples are demanded to reveal the real efficacy of BTX-A usage in diabetic NP. ${ }^{28}$

\section{Conclusions}

Some clinical therapies for NP have emerged over the last decade. With the acceptance of their use, these drugs might become, a part of the routine treatment of NP. Despite a lack of convincing RCTs addressing the efficacy of these new therapies, there is a need for further studies. With advancing knowledge on the pathophysiology of pain, new methods might be proposed, ensuring greater effectiveness of different therapies, with a lower percentage of patients with refractory pain. Doing so, a new paradigm for the treatment of chronic pain will result. Despite the existence of several studies for the relief of NP, pain control continues being a challenge

\section{References}

1. Treede RD, Jensen TS, Campbell JN, et al. Neuropathic pain: redefinition and a grading system for clinical and research purposes. Neurology 2008;70:1630-5.

2. Dworkin RH, Backonja M, Rowbotham MC, et al. Advances in neuropathic pain: diagnosis, mechanisms, and treatment recommendations. Arch Neurol 2003;60:1524-34.

3. Jensen TS, Baron R. Translation of symptoms and signs into mechanisms in neuropathic pain. Pain 2003;102:1-8.

4. Woolf CJ, Mannion RJ. Neuropathic pain: aetiology, symptoms, mechanisms, and management. Lancet 1999;353:1959-64.

5. Schug SA, Goddard C. Recent advances in the pharmacological management of acute and chronic pain. Ann Palliat Med 2014;3:263-75.

6. Schestatsky P, Vidor L, Winckler PB, et al. Promising treatments for neuropathic pain. Arquivos de Neuro-Psiquiatria 2014;72:881-8.

7. Bittar C, Nascimento 0J. Placebo and nocebo effects in the neurological practice. Arquivos de neuro-psiquiatria 2015;73:58-63.

8. Theile JW, Cummins TR. Recent developments regarding voltage-gated sodium channel blockers for the treatment of inherited and acquired neuropathic pain syndromes. Front Pharmacol 2011;2:54.

9. Chang E, Chen X, Kim M, et al. Differential effects of voltage-gated calcium channel blockers on calcium channel alpha-2-delta1 subunit protein-mediated nociception. Eur J Pain 2015;19:639-48.

10. Gorski DH, Novella SP. Clinical trials of integrative medicine: testing whether magic works? Trends in molecular medicine 2014;20:473-6.

11. Greenhalgh T, Howick J, Maskrey N. Evidence based medicine: a movement in crisis? BMJ 2014;348:g3725.

12. [No authors listed]. Acetyl-L-carnitine. Monograph. Altern Med Rev. 2010;15:7683.

13. Sima AA, Calvani M, Mehra M, Amato A. Acetyl-l-carnitine improves pain, nerve regeneration, and vibratory perception in 
patients with chronic diabetic neuropathy an analysis of two randomized placebocontrolled trials. Diabetes Care 2005;28: 89-94.

14. De Grandis D, Minardi C. Acetyl-L-carnitine (levacecarnine) in the treatment of diabetic neuropathy. A long-term, randomised, double-blind, placebo-controlled study. Drugs R D 2002;3:223-31.

15. Shay KP, Moreau RF, Smith EJ, et al. Alphalipoic acid as a dietary supplement: molecular mechanisms and therapeutic potential. Biochim Biophys Acta 2009;1790:1149-60.

16. Packer L, Witt EH, Tritschler HJ. AlphaLipoic acid as a biological antioxidant. Free Radic Biol Med 1995;19:227-50.

17. Mijnhout GS, Kollen BJ, Alkhalaf A, et al. Alpha lipoic acid for symptomatic peripheral neuropathy in patients with diabetes: a meta-analysis of randomized controlled trials. Int J Endocrinol 2012;2012:456279.

18. Ziegler D, Ametov A, Barinov A, et al. Oral treatment with alpha-lipoic acid improves symptomatic diabetic polyneuropathy: the SYDNEY 2 trial. Diabetes Care 2006;29,
2365-70.

19. Lynch ME, Campbell F. Cannabinoids for treatment of chronic non-cancer pain; a systematic review of randomized trials. $\mathrm{Br}$ J Clin Pharmacol 2011;72:735-44.

20. Ware MA, Wang T, Shapiro S, et al. Smoked cannabis for chronic neuropathic pain: a randomized controlled trial. CMAJ 2010;182:E694-701.

21. Rog DJ, Nurmikko TJ, Young CA. Oromucosal delta9-tetrahydrocannabinol/ cannabidiol for neuropathic pain associated with multiple sclerosis: an uncontrolled, open-label, 2-year extension trial. Clin Ther 2007;29:2068-79.

22. Langford RM, Mares J, Novotna A, et al. A double-blind, randomized, placebo-controlled, parallel-group study of THC/CBD oromucosal spray in combination with the existing treatment regimen, in the relief of central neuropathic pain in patients with multiple sclerosis. J Neurol 2013;260: 984-97.

23. Whiting PF, Wolff RF, Deshpande S, et al. Cannabinoids for medical use: a systematic review and meta-analysis. JAMA
2015;313:2456-73.

24. Campbell CM, Kipnes MS, Stouch BC, et al. Randomized control trial of topical clonidine for treatment of painful diabetic neuropathy. Pain 2012;153:1815-23.

25. Rice AS, Dworkin RH, McCarthy TD, et al. EMA401, an orally administered highly selective angiotensin II type 2 receptor antagonist, as a novel treatment for postherpetic neuralgia: a randomised, doubleblind, placebo-controlled phase 2 clinical trial. Lancet 2014;383:1637-47.

26. Linz K, Christoph T, Tzschentke TM, et al. Cebranopadol: a novel potent analgesic nociceptin/orphanin FQ peptide and opioid receptor agonist. J Pharmacol Exp Ther 2014;349:535-48.

27. Ranoux D, Attal N, Morain F, Bouhassira D. Botulinum toxin type A induces direct analgesic effects in chronic neuropathic pain. Ann Neurol 2008;64:274-83.

28. Yuan RY, Sheu JJ, Yu JM, et al. Botulinum toxin for diabetic neuropathic pain: a randomized double-blind crossover trial. Neurology 2009;72:1473-8. 